\title{
3-Dimensional Lightning Observations Using a Time-of-Arrival Lightning Mapping System
}

\author{
William Rison, Paul Krehbiel, Ron Thomas, Tim Hamlin, and Jeremiah Harlin
}

Langmuir Laboratory for Atmospheric Research, Geophysical Research Center, New Mexico Institute of Mining and Technology, Socorro, New Mexico 87801

Copyright (C)2001 Society of Automotive Engineers, Inc.

\begin{abstract}
A lightning mapping system has been developed that locates the sources of VHF radiation from lightning discharges in three spatial dimensions and time. The system consists of several VHF receivers distributed over an area of about $100 \mathrm{~km}$ diameter. The system locates VHF radiation sources over the array with an accuracy of about $100 \mathrm{~m}$. The system locates sources out to $250 \mathrm{~km}$ from the center of the array with reduced accuracy. The observations are found to reflect the basic charge structure of electrified storms.
\end{abstract}

\section{INTRODUCTION}

This paper describes results from a deployable system developed at New Mexico Tech that locates lightning radiation sources in three spatial dimensions and time. The instrument, called the Lightning Mapping Array (LMA), is based on the Lightning Detection and Ranging (LDAR) system developed for use at the NASA Kennedy Space Center [1]. The system measures the arrival time of impulsive VHF radiation at six or more stations and uses the arrival times to locate the sources of the radiation [2]. The LMA takes advantage of GPS technology to measure the arrival times independently at each of the receiving sites. The system was been operated in central Oklahoma during June of 1998 [3], and in central New Mexico from August of 1998 to September of 1999 [4]. From May to August of 2000 the system was operated in western Kansas and eastern Colorado as part of the STEPS (Severe Thunderstorm Electrification and Precipitation Study) project.

\section{SYSTEM OPERATION}

The description of the system below refers to its operation during 2000 as part of STEPS. This deployment featured several enhancements from the previous deployments in Oklahoma and New Mexico.

Thirteen measurement stations were deployed over an area about $80 \mathrm{~km}$ in diameter in the STEPS domain in Kansas and Colorado (Figure 1). Each station detects the peak intensity of VHF radiation in the $6 \mathrm{MHz}$ bandwidth

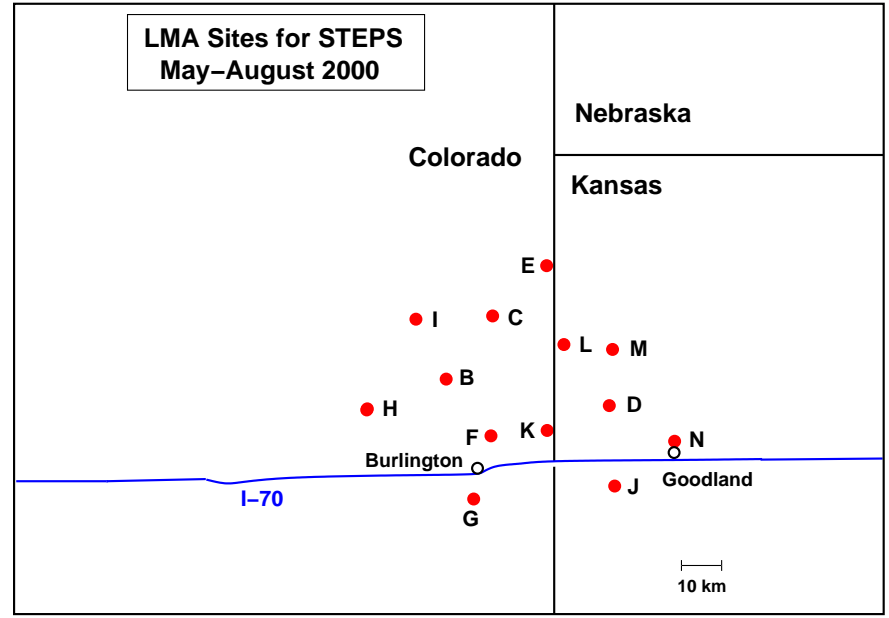

Figure 1. Map of the measurement stations for STEPS in 2000.

of an unused television channel (channel 3, centered at $63 \mathrm{MHz}$ ). The time and magnitude of the peak radiation is recorded during every $100 \mu \mathrm{s}$ time interval that the RF power exceeds a noise threshold. The peak signal times are recorded with $50 \mathrm{~ns}$ time resolution using a $20 \mathrm{MHz}$ digitizer accurately phase locked to the 1 pulse per second output of a GPS receiver. Well-defined events strong enough to be detected at six or more stations are located in three spatial dimensions and time. With the ability to determine the arrival time of a peak once every $100 \mu \mathrm{s}$, the system can locate a maximum of 10,000 sources per second. During active lightning activity over the array, the processing software is able to generate up to 5,000 locations per second. (The system has been operated in a mode where it determines a peak value once every $10 \mu \mathrm{s}$, which generates more detailed images.)

The time of arrival $t_{i}$ of the VHF signal at station $i$ is

$$
t_{i}=t+\frac{\sqrt{\left(x-x_{i}\right)^{2}+\left(y-y_{i}\right)^{2}+\left(z-z_{i}\right)^{2}}}{c}
$$

where $t$ is the time the radiation is emitted from source location $(x, y, z),\left(x_{i}, y_{i}, z_{i}\right)$ is the location of station $i$, and 
$c$ is the speed of light. With the times of arrival of the radiation from a breakdown event measured at six or more stations, the four unknowns $x, y, z$ and $t$ can be found with the least-squares fit to Equation 1. We require at least six stations to participate in each solution in order to provide at least two degrees of redundancy, so local RF noise at a station does not result in a false location.

Figure 2 shows peak power values versus time for an energetic lightning event observed by the LMA. The horizontal scale is divided into the $100 \mu$ s time windows of the measurements and the vertical scale shows the peak power values in $\mathrm{dBm}$. Strong radiation arrived at the nine operational LMA stations during the three-window interval between $995.9 \mathrm{~ms}$ and $996.2 \mathrm{~ms}$. The calculated source time is indicated by the dashed vertical line. The signal strength tended to decrease with distance from the source but varied about this trend due to systematic differences in station sensitivities. The arrival times of normal lightning radiation were consistent with emission from a localized or point source. The statistical distribution of reduced $\chi^{2}$ values indicates overall timing uncertainties of $40-50$ ns rms for the LMA system. Assuming RF radiation from a point source, the timing errors correspond to $50 \mathrm{~m} \mathrm{rms}$ horizontal errors and $100 \mathrm{~m}$ rms vertical errors over the network, with larger errors outside the network. The accuracy of the system was verified by a balloon which carried an impulsive VHF transmitter which generated about one thousand VHF sources per second. Comparison of the known balloon location (determined with an on-board GPS receiver) to the location measured by the LMA confirmed the $50 \mathrm{~m}$ rms horizontal errors and $100 \mathrm{~m}$ rms vertical errors over the network.

The LMA can detect VHF sources over the array when the radiated power exceeds a detection limit of about 1 watt (in the $6 \mathrm{MHz}$ bandwidth of 60 to $66 \mathrm{MHz}$ ). The power radiated by lightning breakdown events detected by the LMA is typically in the range of $1 \mathrm{~W}$ to $10 \mathrm{~kW}$. The distribution of source powers goes as $1 / P$ [5], so there are significantly more low-power events than high-power events. Some breakdown events, such as the one which produced the

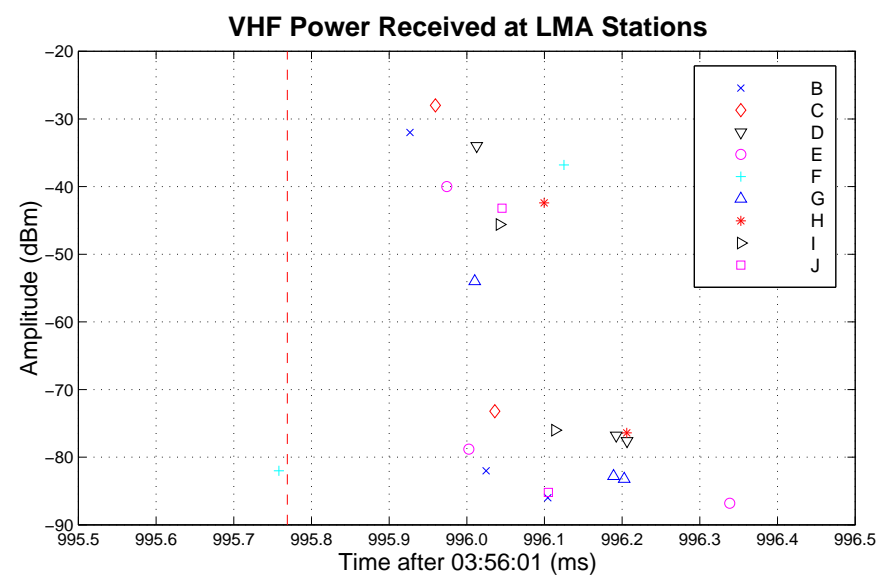

Figure 2. Times and amplitudes of RF peaks recorded at several LMA stations. data in Figure 2, have radiated powers in excess of $10^{6}$ watts.

During the operations in STEPS, all the stations were networked with wireless links to the base station at Site $\mathrm{N}$ in Goodland, Kansas. From the base station we could check on the operation of the remote stations, change noise thresholds as required, and download data to generate real-time images of lightning activity. Although the bandwidth of the wireless links was too slow to transmit all the data to the base station in real time, a sufficient amount of data could be retrieved to provide lightning information useful for STEPS operational use.

\section{OBSERVATIONS OF LIGHTNING DIS- CHARGES}

Figure 3 introduces the format of many of the plots in this paper. This figure shows ten minutes of data from the LMA. During this ten minute interval the LMA located 146,000 radiation sources, of which 49,000 are in the region shown in Figure 3. The $\square$ symbols in the plan view (lower left panel) indicate the locations of LMA stations. The origin of the coordinate system is the center of the array, which is located between Stations $\mathrm{K}$ and L (Figure 1). The panel above the plan view is one vertical cross-section (east-west vs. altitude), and the panel to the right of the plan view is a second vertical cross section (north-south vs. altitude). The top panel shows altitude vs. time. The points are color coded with cool colors
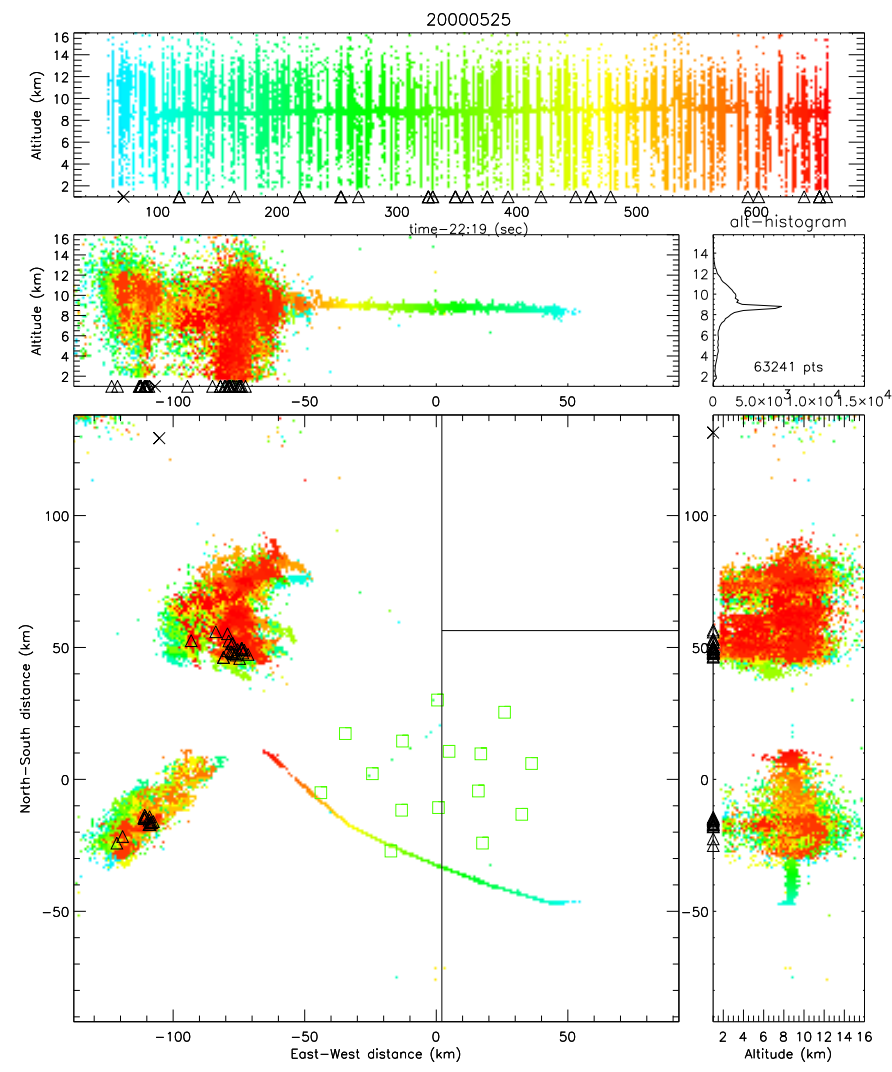

Figure 3. Observations of an airplane avoiding two thunderstorms. 
(blue) earliest in time and hot colors (red) latest in time. The histogram is the number of VHF sources vs. altitude. The triangles $(\Delta)$ in the plan view and the vertical cross sections show the locations of negative cloud-to-ground (CG) discharges as determined by the North American Lightning Detection Network (NALDN) [6]. The triangles in the time-altitude panel show the NALDN times of the CG discharges.

Figure 3 shows two thunderstorm systems to the west of the LMA. Each system is about $50 \mathrm{~km}$ in extent, with most of the located VHF sources at altitudes between 6 and $12 \mathrm{~km}$. The continuous track in the southern part of the plan view is VHF radiation from an commercial airplane. When an airplane flies through a cirrus cloud, the impact of ice crystals electrically charges the plane. When the electric fields on the plane become large enough, an electrical breakdown is generated which discharges the plane. The LMA can locate the stronger of these electrical discharges. For the example shown in Figure 3, the LMA located about 15 discharges per second from the plane. The peak radiated power from the discharges located by the LMA was 1 to 10 watts (in a $3 \mathrm{MHz}$ bandwidth centered at $63 \mathrm{MHz}$ ). The detection limit of the LMA is about 1 watt, so lower-powered discharges would not have been located by the LMA. Because the strongest discharges from airplanes is about 10 watts, discharges generated by planes over $75 \mathrm{~km}$ from the center of the array are below the LMA detection threshold.

TYPICAL LIGHTNING DISCHARGES - The electrical structure of a typical isolated thunderstorm is shown in Figure 4. Such a thunderstorm has a tripole charge struc- ture, with a main negative charge region at 6 to $8 \mathrm{~km}$ altitude, an upper positive region at 8 to $12 \mathrm{~km}$, and a lower positive region at 4 to $6 \mathrm{~km}[8]$.

Intracloud Discharges - Most lightning is intracloud (IC) lightning, and occurs between the main negative and upper positive charge regions. The initial breakdown occurs in the high field region at the top of the upper negative region at about $8 \mathrm{~km}$ altitude. Negative streamers (red in Figure 4) propagate vertically upward into the positive charge region, and spread out horizontally, collecting charge from pockets in the upper positive charge region. Positive streamers (blue) propagate down into, then horizontally through the negative charge region. A typical IC discharge will transfer $20 \mathrm{C}$ of charge. All the charge is transferred through the vertical channel established by the initial breakdown. Figure 5 shows a typical IC discharge as imaged by the LMA. The discharge had a bi-level structure typical of many IC flashes; the lower and upper levels correspond to the main negative and upper positive charge regions of the storm, respectively [9]. Of the 547 radiation events located during the flash, most were in the upper positive charge region and relatively few were in the lower, negative charge region (see the altitude histogram panel). This asymmetry is typical of observations by VHF location systems. Positive charge regions are penetrated by negative polarity breakdown, which is inherently noisier at RF than positive breakdown into negative charge regions $[9,10]$. The difference is sufficiently pronounced that one can usually determine the polarity of the breakdown and the sign of a charge region from the relative number of located sources.

While the electrical structure of small, isolated thunder-

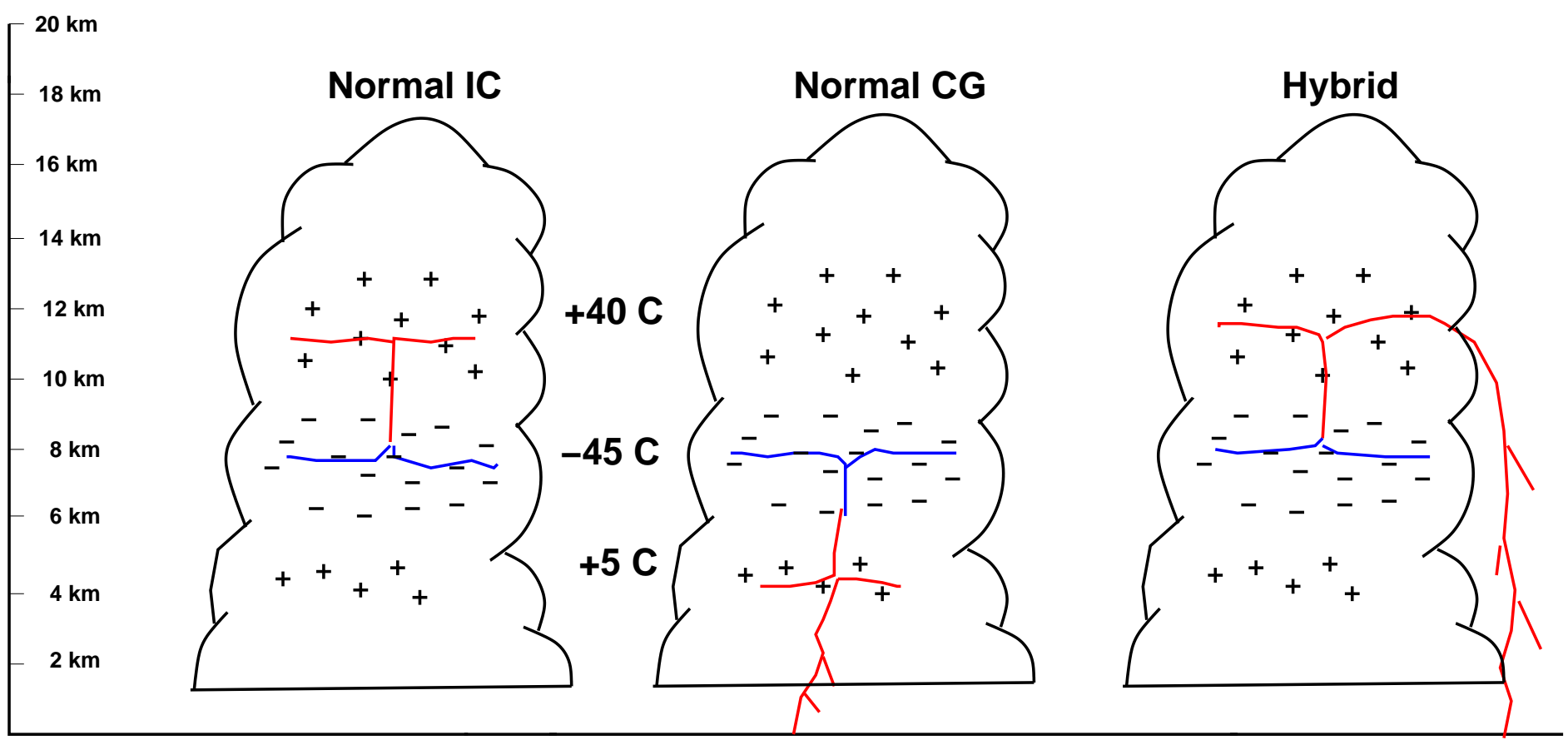

Figure 4. Electrical structure of an isolated summer thunderstorm, with negative (red) and positive (blue) streamers. Adapted from Krehbiel [7]. 

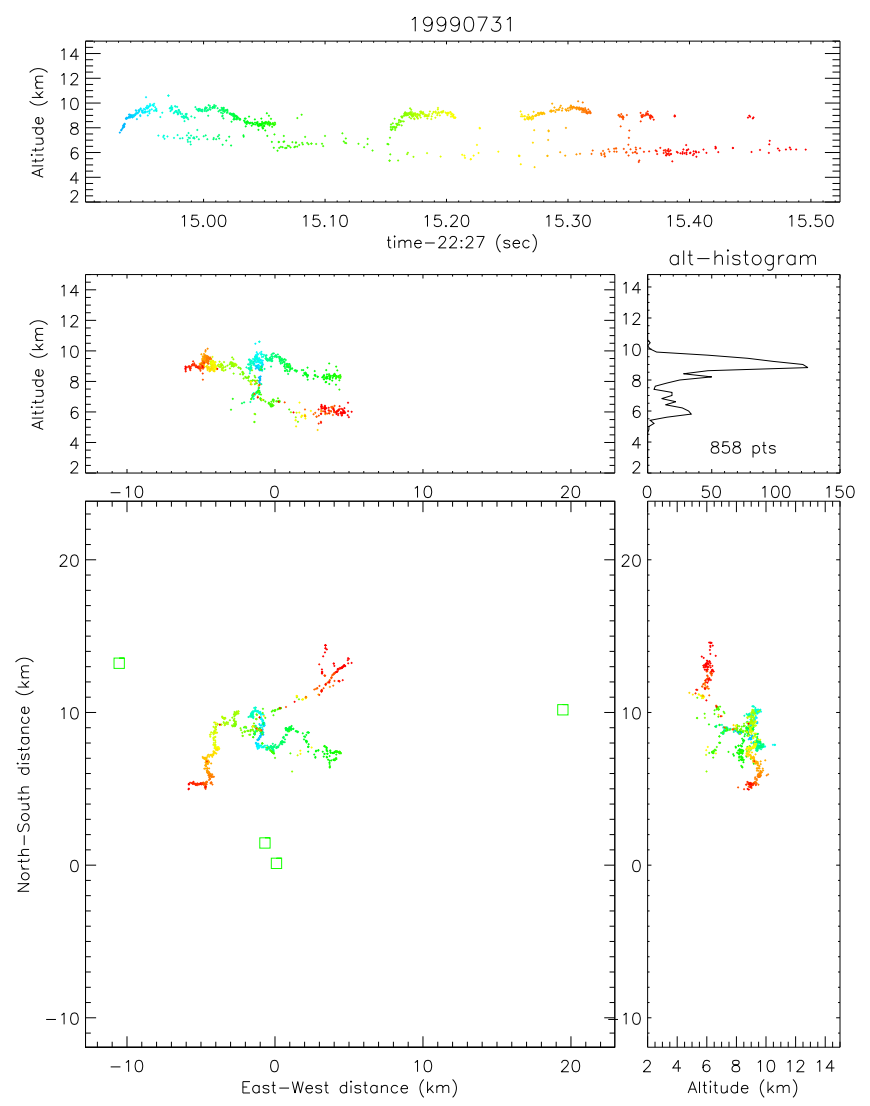

Figure 5. A typical IC discharge.
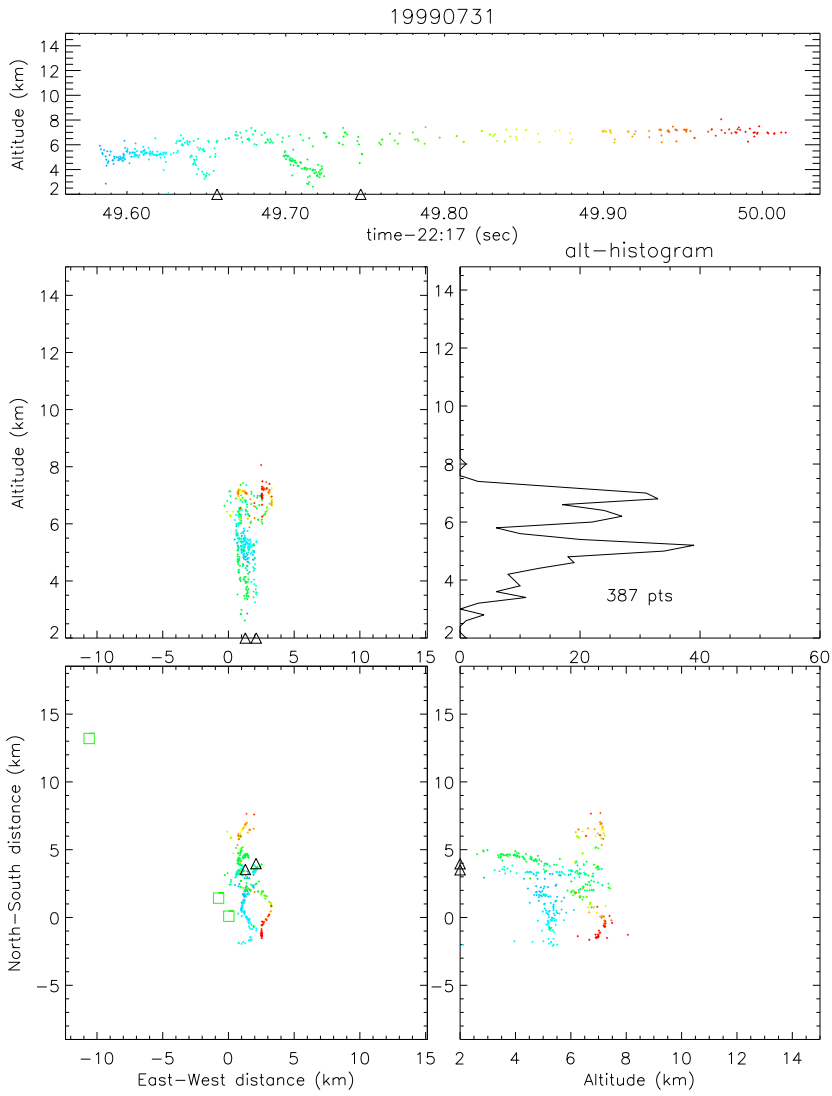

Figure 6. A typical CG discharge.
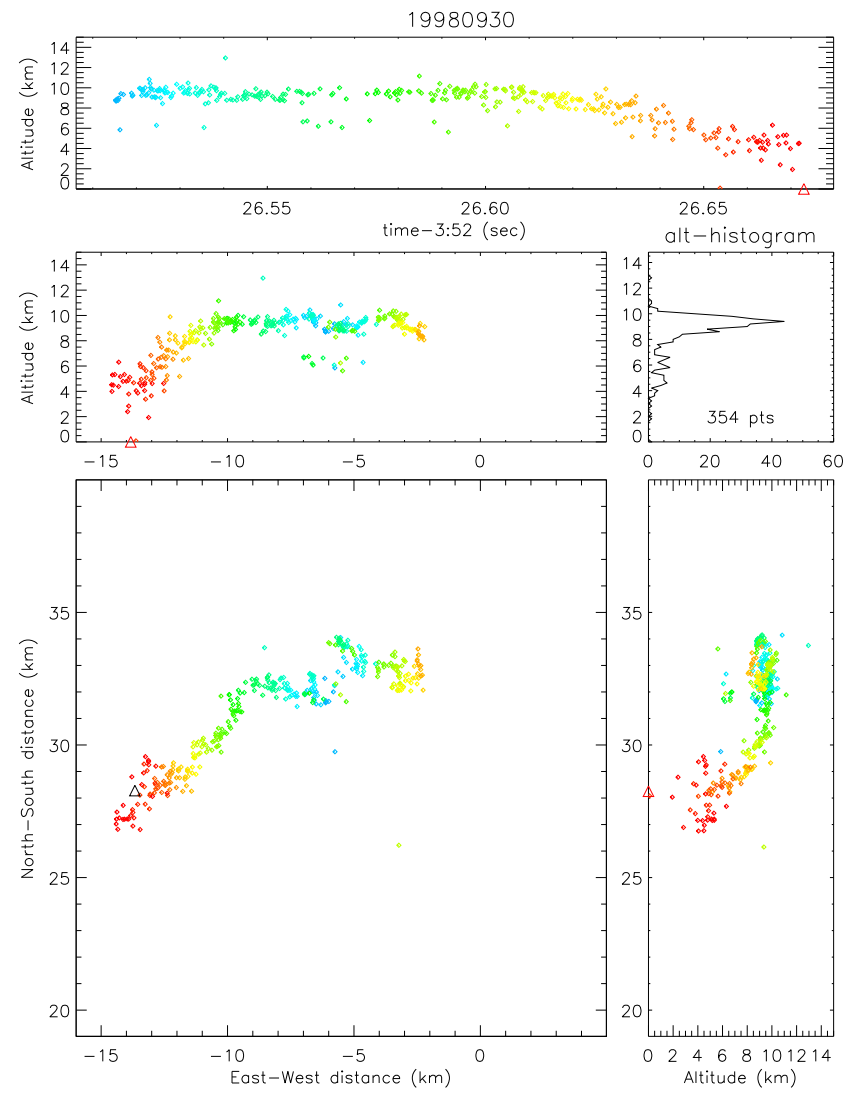

Figure 7. A hybrid discharge.
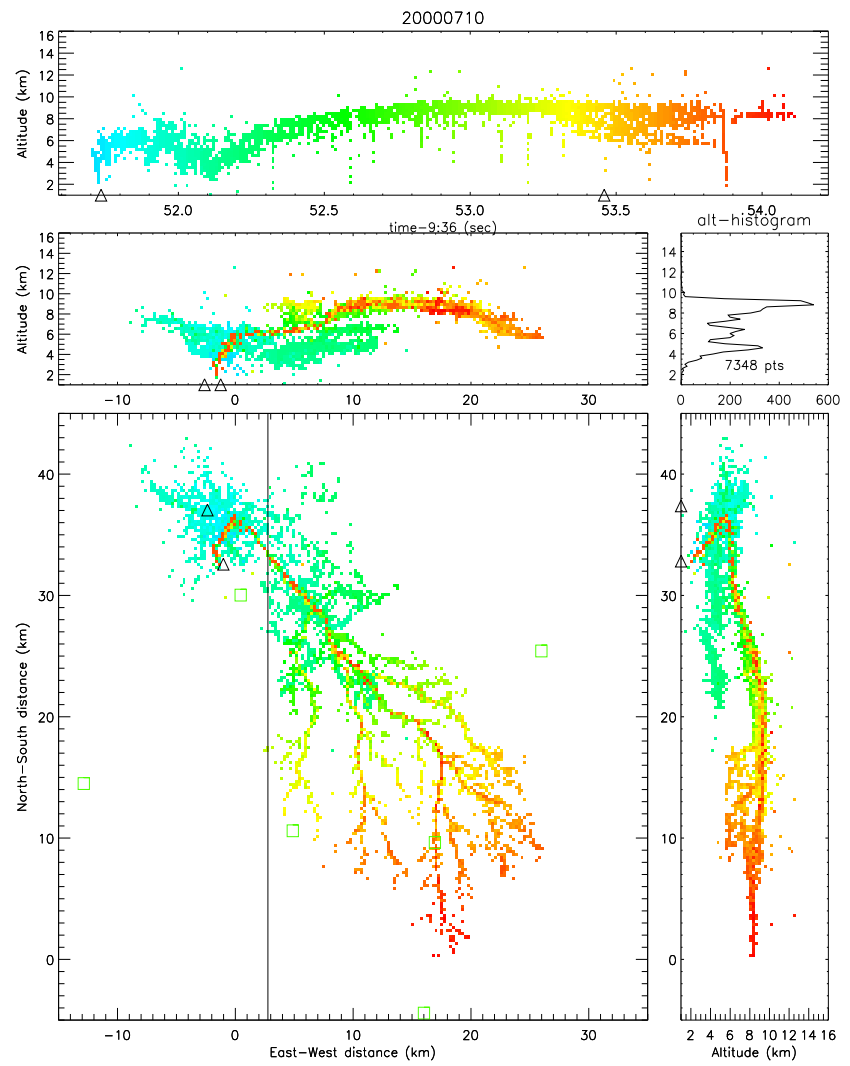

Figure 8. A complicated CG discharge. 
storms usually have that tripole structure shown in Figure 5, larger thunderstorm systems have significantly more complicated electrical structure [11]. In many storms observed in the Midwest during the STEPS project, the electrical structure appears to be inverted from that of Figure 5.

Cloud-to-Ground Lighting - Cloud-to-ground (CG) lightning is initiated in the strong field region between the main negative and lower positive charge regions. The initial breakdown starts at about $6 \mathrm{~km}$, and propagates vertically downward into the lower positive region, and then continues on to ground, directed by the fields between the main negative charge region in the cloud and the induced positive charge induced on the ground. Figure 6 shows a typical CG discharge as imaged by the LMA. The initial breakdown was at the base of the main negative charge region at $6 \mathrm{~km}$, from which streamers propagated into the lower positive charge region between 4 and $6 \mathrm{~km}$. About $50 \mathrm{~ms}$ after the initial breakdown, a stepped leader progressed out of the lower positive region to ground. The VHF source locations of the stepped leader are consistent with the time and location of the associated return stroke, as identified by the NALDN $(\Delta)$. A second stepped leader started about $30 \mathrm{~ms}$ after the first return stroke, and the associated second return stroke was $50 \mathrm{~ms}$ later. Positive streamers developed into the main negative charge region (between 6 and $8 \mathrm{~km}$ ) in the latter stages of the discharge.

Hybrid Discharges - Many discharges are hybrid, in that they start out as an IC discharge, with a negative leader in the late stage of the flash finding a way to ground. In some instances a negative leader can propagate out of the upper positive charge region to ground, outside the main body of the thundercloud. Figure 7 shows such a hybrid discharge. The initial negative breakdown was at the top of the main negative charge region, and developed vertically upward into the upper positive region. A negative streamer propagated out of the western part of the upper positive region, and came to ground about $10 \mathrm{~km}$ southwest of the region of initial breakdown. Again, the located radiation sources from the leader to ground agree with the the NALDN location of the associated return stroke.

More Complicated Discharges - The lightning discharges shown above were in small isolated thunderstorms in New Mexico. In larger thunderstorm systems, such as frequently occur in the Midwest, individual lightning discharges can be much more extensive and complicated. Figure 8 shows a CG discharge in a thunderstorm in eastern Colorado and western Kansas. This single discharge, which lasted for about 2.5 seconds, had over 7,000 VHF sources located by the LMA, and had a horizontal extent of over $40 \mathrm{~km}$. It produced about 15 return strokes, as indicated by the numerous stepped and dart leaders to ground (although the NALDN detected only two return strokes), and extensive positive streamers propagating into the negative charge region. The LMA has recorded numerous positive $\mathrm{CG}$ discharges with horizontal extents in excess of $75 \mathrm{~km}$.

\section{OBSERVATIONS OF THUNDERSTORMS}

In addition to showing the structures of individual lightning discharges, the LMA can provide a great deal of information about thunderstorm systems. To most effectively see this type of information, it is useful to display several minutes of LMA data. When doing so, plotting individual radiation sources obscures the information in the plots, because there are so many sources that newer source points are plotted over older points (as in Figure 2). Figure 9 shows 10 minutes of LMA data, plotted as the log of the density of sources (the number of sources per unit area). In these types of plots, the locations of the most intensive lightning activity becomes readily apparent. Time animations of these images show the development of lightning activity in a thunderstorm system. As seen in Figure 9, the LMA located in nortwestern Kansas and eastern Oklahoma, is able to observe thunderstorm activity in norther New Mexico, over 250 km away.

Figure 10 shows 4 minutes of data for a supercell thunderstorm on June 29, 2000. An interesting feature of the

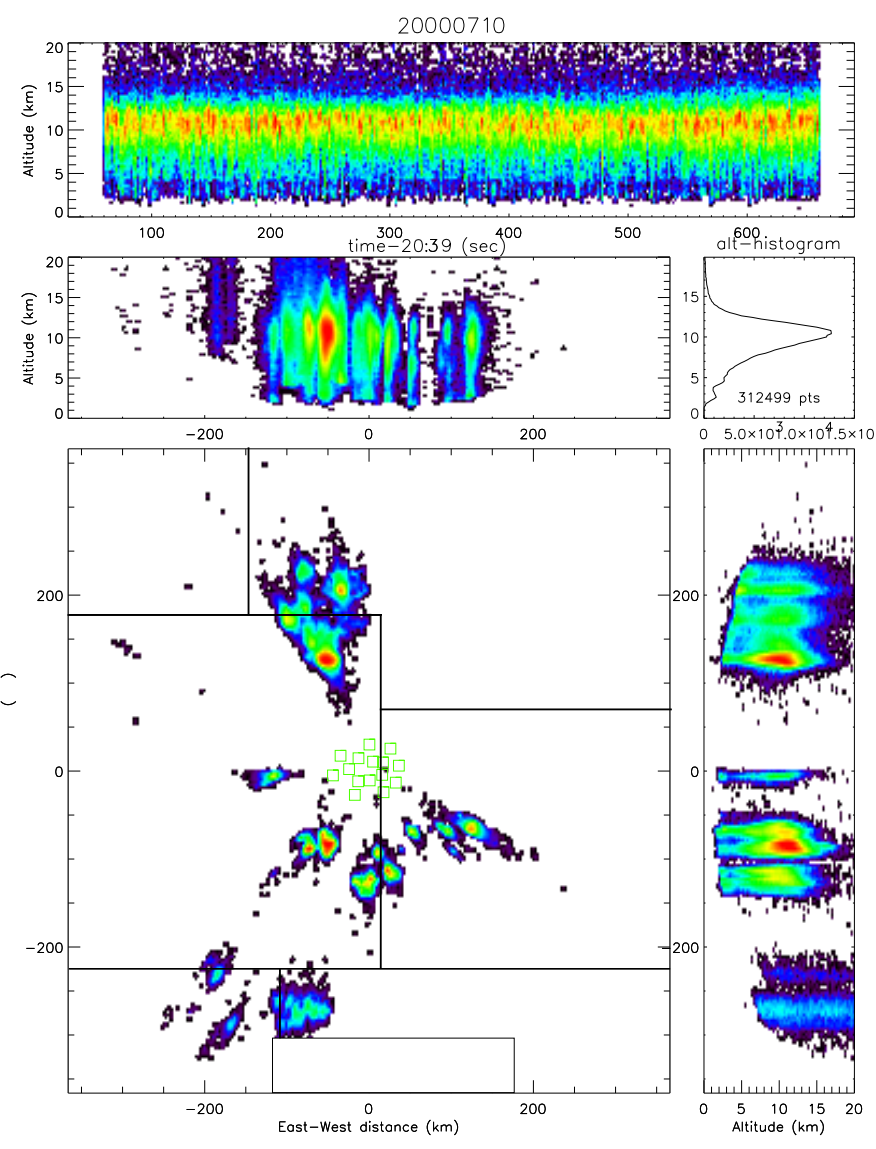

Figure 9. 10 minutes of LMA data plotted as the log of the number of LMA sources per unit area. An area with a high density of sources indicates a region of intense convective activity. 
plot is the area with very little lightning activity on the western side of the supercell. This lightning-free hole represents a region of exceptionally strong convection, with updraft velocities exceeding $150 \mathrm{~km} / \mathrm{hr}$. These strong updrafts carried precipitation particles out of the region, leaving a particle-free, and hence charge-free, volume. Thus, there was no charge to support the development and propagation of streamers. The only lightning activity in this updraft region was at very high altitudes (higher than $15 \mathrm{~km}$ ), as the overshooting top driven by the intense convection penetrated into the stratosphere. About 10 minutes after the time shown in Figure 10 a tornado developed on the southwestern edge of the lightning-free region. During the deployments of the LMA in Oklahoma and STEPS, we have observed lightning associated with four supercells which produced tornadoes. In all four cases lightning-free holes with associated highaltitude lightning preceded the formations of the tornadoes by about 15 minutes.

\section{CONCLUSIONS}

With the ability to determine event times with high accuracy, using the timing capabilities of local GPS receivers, we have developed a deployable system for detailed 3dimensional mapping of lightning in thunderstorms. The

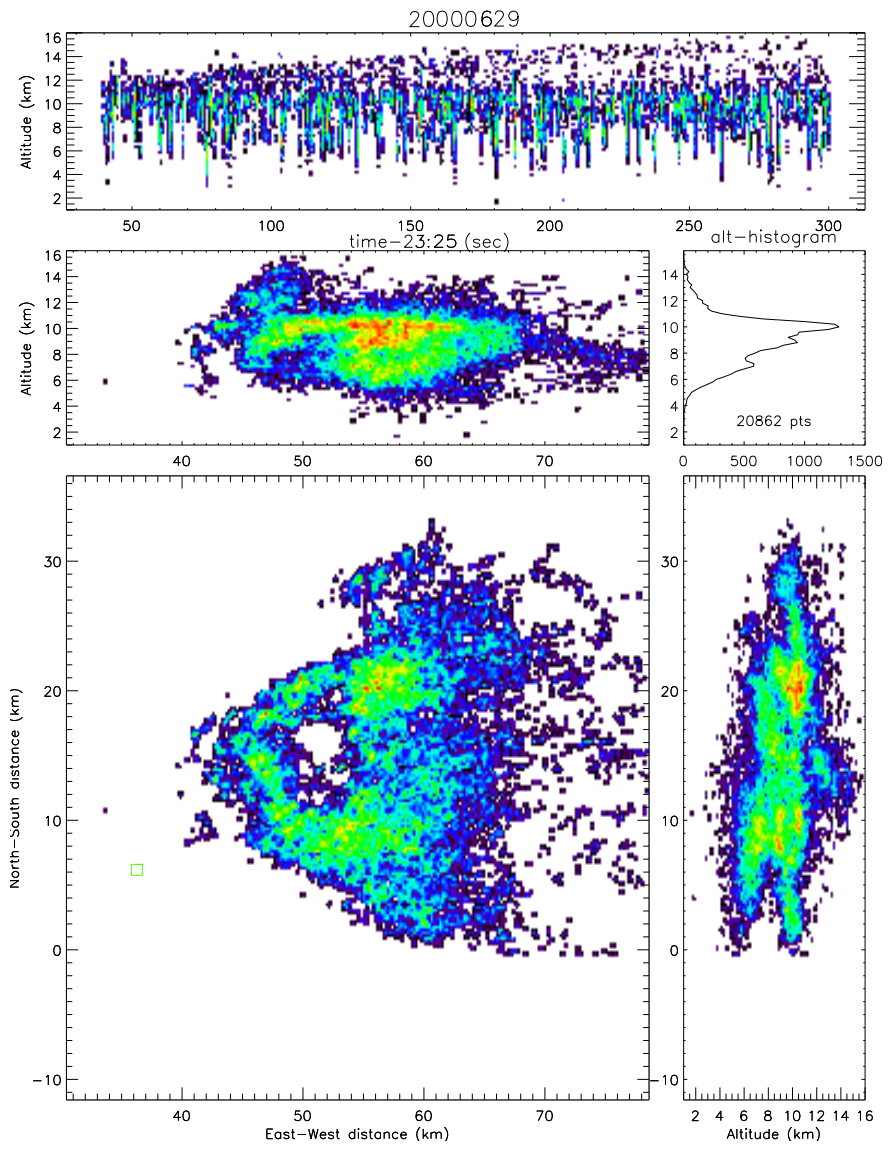

Figure 10. 4 minutes of LMA data showing a lightning-free region in a supercell thunderstorm. A tornado formed on the southwestern edge of the lightning-free region $10 \mathrm{~min}-$ utes later. system provides $100 \mathrm{~m}$ accuracy for the location of lightning-generated VHF radiation, and locates several hundred to tens of thousands of radiation sources per lightning discharge. The LMA provides detailed images of individual lightning discharges, and shows the electrical development of thunderstorm systems. Because severe thunderstorms have periods of intense lightning activity, instruments such as the LMA may be useful in providing some advance warning of severe weather.

\section{ACKNOWLEDGMENTS}

The development and initial deployment of the LMA was supported by the U.S. National Science Foundation under ARI Grant ATM-9601652, and by the U.S. Air Force Office of Scientific Research under Grant F49620-96-10304. Operation of the LMA during STEPS was supported by the U.S. National Science Foundation under Grant ATM-9912073.

\section{REFERENCES}

[1] Maier, L., C. Lennon, T. Britt and S. Schaefer, LDAR system performance and analysis, Proceedings of the International Conference on Cloud Physics, Am. Meteorol. Soc., Boston, Mass., Dallas, Tex., Jan 1995.

[2] Proctor, D. E., A Hyperbolic System for Obtaining VHF Radio Pictures of Lightning, J. Geophys. Res., 76, 1478-1489, 1971.

[3] Krehbiel, P., R. Thomas, W. Rison, T. Hamlin, J. Harlin, and M. Davis, GPS-based mapping system reveals lightning inside storms, Eos, Transactions of the American Geophysical Union, 81, 21-25, 2000.

[4] Rison, W., R. Thomas, P. Krehbiel, T. Hamlin, and J. Harlin, A GPS-based three-dimensional lightning mapping system: Initial observations in central New Mexico, Geophys. Research Letters, 26, 3573-3576, 2000.

[5] Thomas, R., P. Krehbiel, W. Rison, T. Hamlin, J. Harlin, and D. Shown, VHF source powers radiated by lightning discharges, Geophys. Research Letters, 28, 143-146, 2001.

[6] Cummins, K. L., M. J. Murphy, E. A. Bardo, W. L. Hiscox, R. B. Pyle and A. E. Pifer, A combined TOA/MDF technology upgrade of the U.S. National Lightning Detection Network, J. Geophys. Res., 103, 9035-9044, 1998.

[7] Krehbiel, P., R., The eletrical structure of thunderstorms, in The Earth's Electrical Environment, National Academy Press, pp. 90-113, 1986.

[8] Williams, E. R. The tripole structure of thunderstorms, J. Geophys. Res., 94, 13,151-13,167, 1989.

[9] Shao, X. M., and P. R. Krehbiel, The spatial and temporal development of intracloud lightning, J. Geophys. Res., 101, 26,641-26,668, 1996. 
[10] Mazur, V., and L. Ruhnke, Common physical processes of in natural and artificially triggered lightning, J. Geophys. Res., 98, 12,913-12,930, 1993.

[11] Stolzenburg,M., W. D. Rust B. F. Smull and T. C. Marshall, Electrical structure in thunderstorms convective regions, 1 , Mesoscale convective systems, J. Geophys. Res., 103, 14,059-14,078, 1998.

\section{ADDITIONAL SOURCES}

For more information on the New Mexico Tech Lightning Mapping Array, see http://www.lightning.nmt.edu. 